\title{
Contratos plan, pactos territoriales: concertar el desarrollo por contrato
}

Plan Contracts, Territorial Pacts: Agreement for Development by Contract

Contratos plan, pactos territoriais: concertar o desenvolvimento por contrato

Luis Arturo de la Torre Sendoya*

Recibido: 9 de octubre de 2018

Aprobado: 2 de diciembre de 2019

https://doi.org/10.12804/revistas.urosario.edu.co/territorios/a.7385

Para citar este artículo:

De la Torre Sendoya, L. A. (2020). Contratos plan, pactos territoriales: concertar el desarrollo por contrato. Territorios, (43), 1-17. https://doi.org/10.12804/revistas.urosario.edu.co/territorios/a.7385

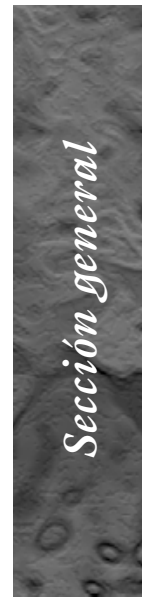

* Investigador asociado de ART-Dev, U. Paul Valéry, Montpellier (Francia). Correo electrónico: luisarl@yaboo.fr. ORCID: https://orcid.org/00000002-9435-6889 
Palabras clave

Contractualización; contratos plan; contratos de acción pública; desarrollo regional; territorialización; gobernanza multinivel.

Keywords

Contractualization; contratos plan; public action contracts; regional development; territorialization; multilevel governance.

Palavras-chave

Contratualização; contratos plan; contratos de ação pública; desenvolvimento regional;

territorializaçã 0 ; governança multinível.

\section{RESUMEN}

La fijación de objetivos negociados por contratos de acción pública a través de instrumentos tales como los contratos plan, los contratos paz y ahora los pactos territoriales colombianos puede constituir una respuesta para territorializar el manejo del desarrollo regional. En este texto, resultado de una investigación doctoral (2018), se presentan los aportes o innovaciones de esta nueva figura de la acción pública y los obstáculos que las experiencias hoy conocidas a nivel internacional nos revelan.

\section{ABSTRACT}

The setting of negotiated objectives by public action contracts through instruments like contratos plan, contratos paz and now the Colombian pactos territoriales may constitute a response to territorialize the regional development management. This text, as a result of a PhD research (2018), presents the contributions or innovations of this new figure of public action but also the obstacles that the experiences known today at international level reveal us.

\section{RESUMO}

A fixação de objetivos negociados por contratos de ação pública através de instrumentos tais como os contratos plan, os contratos paz e agora os pactos territoriais colombianos pode constituir uma resposta para territorializar a gestão do desenvolvimento regional. Neste texto, resultado de uma pesquisa doutoral (2018), se apresentam os aportes ou inovações desta nova figura da ação pública e os obstáculos que as experiências hoje conhecidas no nível internacional nos revelam. 
Introducción: la

'contractualización', una

respuesta instrumental para

el desarrollo territorial

Con la implementación a partir de enero de 2012 en siete territorios piloto de la medida contratos plan, Colombia abrió una nueva etapa en materia de coordinación interinstitucional para el desarrollo. Tal como han quedado definidos por la normativa vigente, ${ }^{1}$ los contratos plan son un mecanismo de coordinación, planificación y ejecución de proyectos de desarrollo territorial, liderado por el gobierno nacional ${ }^{2}$ o por las propias entidades territoriales a través de sus esquemas asociativos territoriales. ${ }^{3}$

Vale la pena recordar que los siete contratos plan pilotos (figura 1) movilizaron alrededor de 12,7 billones de pesos provenientes de la nación y de las entidades territoriales para la ejecución de 678 proyectos de desarrollo en $16 \mathrm{sec}$ tores del desarrollo territorial. Los cinco sectores con mayor cantidad de proyectos fueron agua potable y saneamiento básico $(17,9 \%)$, infraestructura vial y transporte $(17,6 \%)$, educación $(15,68 \%)$, salud y protección social $(11,98 \%)$ y agropecuario $(11,54 \%)$; pero la inversión en infraestructura vial captó más de dos tercios de los recursos movilizados $(68,3 \%)$. La participación media de la nación ronda el $89 \%$ de los recursos invertidos (CNC, 2017).

Con base en este mecanismo, el segundo gobierno Santos implementó dentro del
PND 2014-2018 ${ }^{4}$ una segunda generación adaptada a las zonas más expuestas del posconflicto, los contratos paz. Los seis nuevos contratos paz (figura 1) incluían recursos por 6,5 billones de pesos.

El mismo esquema reglamentario y las lecciones aprendidas en los primeros años de implementación de la medida llevaron al gobierno de Iván Duque a promover en el PND 2018-2022 la figura de los pactos territoriales (figura 2), una tercera generación del dispositivo contractual, pieza clave dentro de la ambiciosa propuesta de regionalización del desarrollo que parece anunciar una nueva etapa de la descentralización. El gobierno notificó para 2019 una inversión de $\$ 3,1$ billones en la ejecución de 260 proyectos, especialmente en transporte, agricultura y desarrollo rural, educación, vivienda y salud.

La irrupción de la nueva medida parece indicar que, frente a los desafíos actuales del desarrollo regional, los gobiernos han decidido combinar las respuestas 'institucionales' que se aplican desde hace 50 años, en particular la planificación legislativa ${ }^{5}$ y la descentralización política, ${ }^{6}$ con las respuestas 'instrumentales' de las cuales los contratos plan son una expresión operativa. Nos referimos aquí a los "instrumentos de acción pública" tal como los conciben los politólogos franceses Pierre Lascoumes y Patrick Le Galès, quienes los definen como "instituciones estructuradoras de acciones públicas y políticas que reposan sobre marcos de pensamiento o matrices cognitivas
Las fuentes legales iniciales de la medida son la Ley 1450 del 16 de junio 2011, que expide el PND 2010-2014 "Prosperidad para todos” (art. $8^{\circ}$ ); la Ley Orgánica de Ordenamiento Territorial (LOOT) del 28 de junio de 2011 (arts. $9^{\circ}, 12,13,14$ y 18); y el Decreto 819 del 25 de abril 2012, "por el cual se dictan disposiciones sobre la elaboración e implementación de los contratos plan”.

${ }^{2}$ Si se toma como fuente la ley del PND 2010-2014.

${ }^{3}$ Como se prevé en la LOOT.

${ }^{4}$ Los articulos 198 (contratos plan) y 199 (mecanismos para la ejecución de los contratos plan) de la ley del PND 2014-2018, y los decretos 240 del 4 de mayo de 2016, que crea el Fondo Regional de los Contratos Plan, $y$ el 1675 del 21 de octubre de 2016, que redefine las reglas de elaboración $y$ financiación de los contratos plan adoptando la apelación 'contratos plan para la paz' o contratos paz.

${ }^{5}$ Tomando en cuenta solo los paises de economía no administrada, los sistemas de planificación, programación y presupuestación (planning, programming

\section{$\Longrightarrow$}

territarias 43

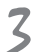


$\Leftarrow$

and budgeting systems, PPBS) se aplican desde el final de los años cincuenta en la administración de Estados Unidos, Canadá, Francia y en la gran mayoria de los paises europeos. En América Latina aparecen en los años sesenta vinculados a una cierta concepción del Estado de bienestar inspirada en los PPBS norteamericanos (Tavares \& Berretta, 2006).

${ }^{6}$ Los procesos de descentralización coexisten con los dispositivos de planificación legislativa, y el primer informe mundial sobre el tema publicado en 2007 por la organización multilateral Ciudades y Gobiernos Locales Unidos (Barcelona, 2007) pone claramente en evidencia el carácter global de la descentralización. Según este informe, entre los años ochenta y noventa, más de 130 paises estaban dotados de gobiernos locales con asambleas y ejecutivos politicos directamente elegidos por la población. A partir del año 2000, la ONU contabilizaba 189 miembros organizados con niveles locales de gobierno electos, con lo cual los paises descentralizados pasaron a ser mayoría en el mundo.

\section{tersitarias 43}

Figura 1. Los contratos plan pilotos y los contratos paz
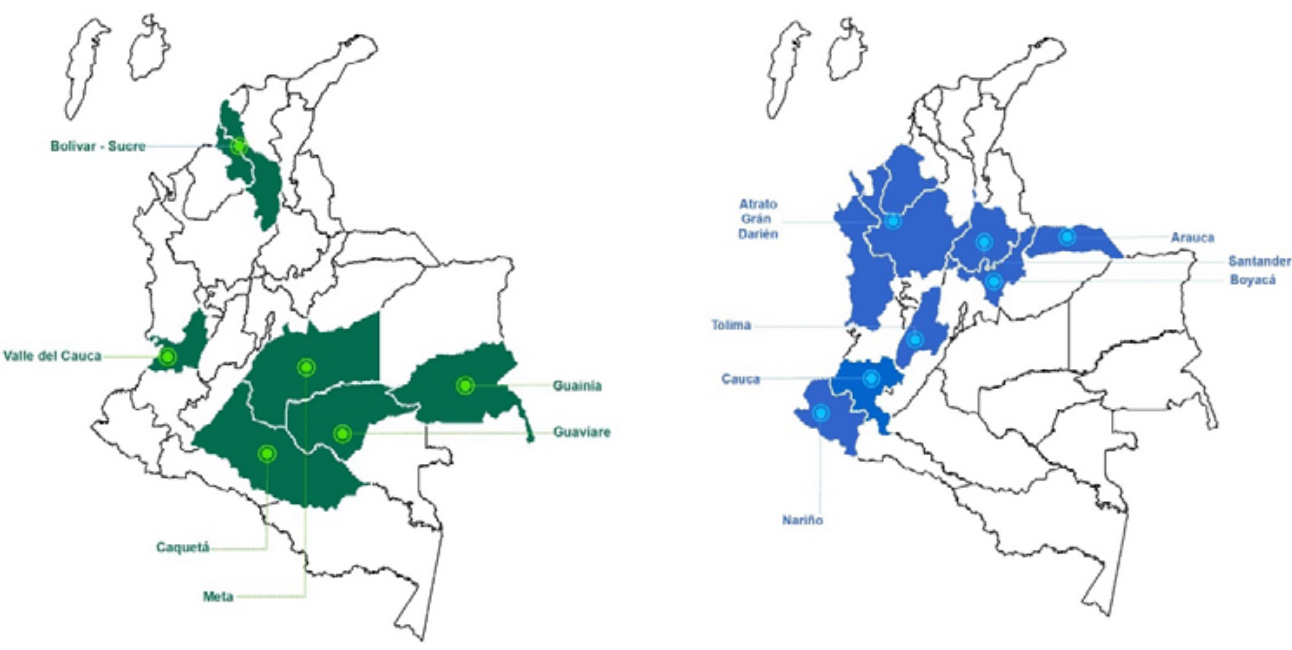

(c) Contratos Paz

Contratos Plan Pilotos

Fuente: DNP (2019)

Figura 2. Los nueve pactos territoriales del PND 2018-2022

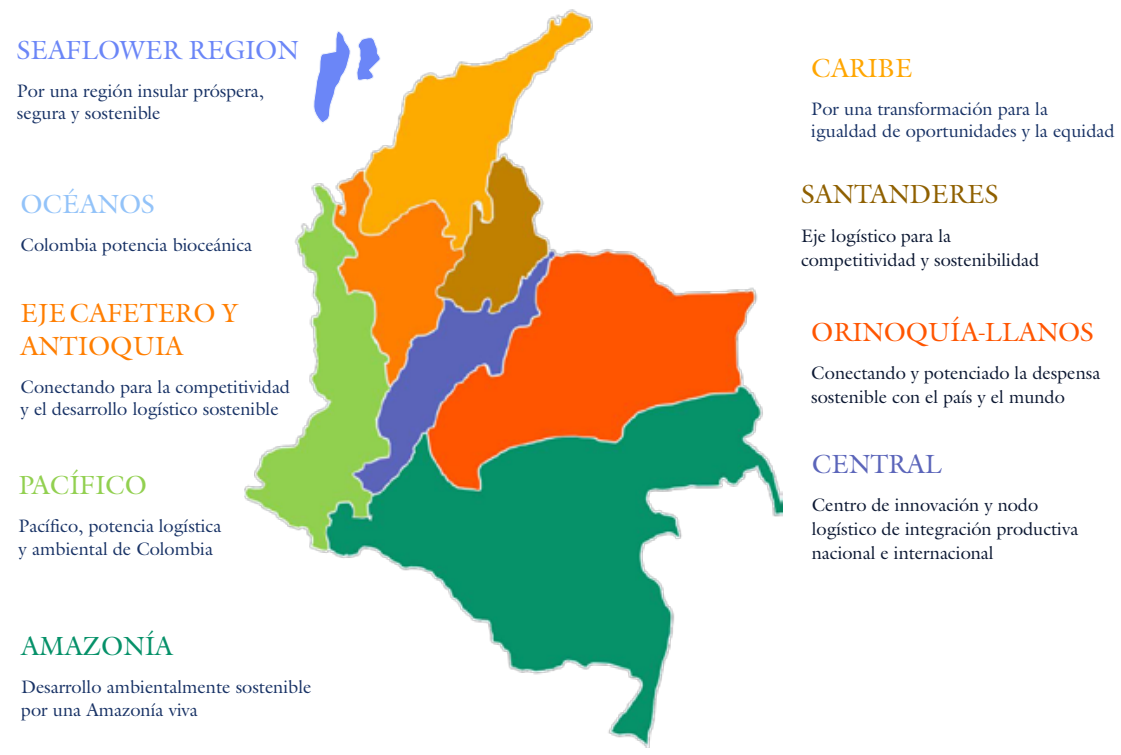

Fuente: DNP (2019). 
y normativas susceptibles de ser empleados en la actividad gubernamental".

En realidad, vistos a escala internacional, los instrumentos asimilables a la noción de 'contrato' no son un fenómeno reciente. Son muchos los países en los cuales su implementación ha permitido territorializar el ejercicio de planificación nacional y ha generado procesos de proyección multisectorial que fomentan la libre asociación entre entidades territoriales. De ello daba cuenta en 2007 el informe de la OCDE que hizo un balance internacional de dos décadas de ese tipo de procesos que proponemos denominar en este artículo utilizando un neologismo de uso frecuente en la ciencia política francesa y anglosajona, la contractualización para el desarrollo regional (Charbit \& Mizell, 2007). ${ }^{8}$

Para definirlos precisamente, tenemos que aclarar que los contratos de los que hablamos se diferencian, en su forma y en su perfeccionamiento procedimental, de la categoría de los 'negocios jurídicos' en la cual entran, en el campo administrativo, los diferentes mecanismos de la contratación pública y, en Colombia, por ejemplo, los "convenios interadministrativos" (González, 2013). Se trata, según la expresión del politólogo francés Jean Pierre Gaudin, de "contratos de acción pública" (Gaudin, 1999) que se presentan como acuerdos de intervención o de inversión entre los actores implicados en una acción para el desarrollo de un determinado territorio, en cuyo proceso de elaboración se respetan cuatro etapas:

1) una fase preliminar de diagnóstico territorial (cuyas conclusiones deben compartir los actores involucrados en el contrato);

2) una fase de negociación que finaliza con la adopción consensuada de una serie de objetivos de acción (que pueden ser una inversión, un proyecto o un programa estructurado de proyectos);

3) un compromiso sobre dos puntos esenciales: un calendario de realización que en general se inscribe entre el tiempo corto de la anualidad presupuestal y el tiempo largo de la planificación, y las contribuciones conjuntas de las partes implicadas en el acuerdo bajo la forma de aportes financieros o de recursos humanos o técnicos;

4) todo esto escrito en un texto firmado por las partes.

Los contratos de acción pública son el instrumento por excelencia de la gobernanza multinivel, ${ }^{9}$ pues suponen un proceso de coproducción de la acción pública entre los diferentes actores involucrados en el desarrollo territorial, en el cual incluso pueden intervenir el sector privado o los representantes de la sociedad civil, como vamos a verlo en ciertos ejemplos extranjeros. La pluralidad de instrumentos de este tipo ha generado un enfoque renovado de la planificación del desarrollo del cual emerge una forma de
Citado por Dumoulin y Saurugger (2010, p. 16).

$8 \Upsilon$, más recientemente, un working paper sobre la "gobernanza compartida" en el desarrollo territorial (Charbit \& Romano, 2017).

${ }^{9}$ Consideramos la noción degobernanza multinivel en el sentido de las reglas de cooperación entre niveles de gobierno por contraste con el proyecto descentralizador original que establece las reglas de repartición exclusiva de las competencias entre niveles de gobierno ( Le Galès, 2019).

\section{territarios 43}


${ }^{10}$ La creación de los contratos plan constituye un caso singular de policy mobility que investigué en la tesis de doctorado sustentada en la Universidad de Montpellier III en diciembre de 2018 (De la Torre, 2018, https:// hal.archives-ouvertes. fr/ tel-02113912).

11 La información aqui analizada figura en parte en el documento elaborado para el DNP "Marco conceptual para la implementación del instrumento contratos plan en Colombia” (De la Torre, 2012).

territarios 43 acción pública en la que están íntimamente ligadas las cuatro fases de elaboración antes mencionadas.

En Colombia, la utilización de los contratos de acción pública es aún incipiente. No es ajeno a esta circunstancia el que la matriz del nuevo instrumento, los contratos plan, sea de implementación reciente y que haga explícitamente referencia a un modelo importado, el de los contrats de plan Etat région (CPER) franceses. De manera que en la genealogía de la medida hay un componente de transposición cuyo relato está aún por contarse. ${ }^{10}$ Por estas mismas razones es igualmente importante, de cara al futuro, volver de manera crítica sobre varias experiencias extranjeras documentadas para la elaboración del instrumento colombiano, ${ }^{11}$ para luego entender cómo la concertación de objetivos por contratos de acción pública puede aportar una respuesta a los retos actuales del desarrollo regional, pero, igualmente, de qué forma este mecanismo puede armonizar, fortalecer o hacer más eficientes las relaciones entre los gobiernos nacional y local en Colombia.

Nuestro objetivo en este texto es describir cuáles son los aportes o innovaciones de la contractualización para el desarrollo y cuáles son los obstáculos que las principales experiencias conocidas en el ámbito internacional nos muestran para el buen manejo del desarrollo territorial.

\section{Los aportes de los contratos de acción pública}

Al analizar el contenido de las diferentes experiencias internacionales, se podrían considerar cuatro tipos de aportes de los contratos de acción pública al manejo del desarrollo regional, que resumiríamos en la fórmula siguiente: los contratos de acción pública aplicados al desarrollo territorial tienen la capacidad de integrar las apuestas de los actores del territorio, generando dinámicas de participación que definen el marco de una nueva gobernanza más inclusiva en procesos que apuntan a la sostenibilidad del desarrollo. Tomemos en cuenta separadamente cada uno de los cuatro componentes de esta observación.

El primer aporte radica en que la utilización de estos instrumentos ha llevado a los diferentes actores a compartir la visión del territorio en el cual todos intervienen. Por ser el resultado de un diálogo que conducen y animan las autoridades públicas nacionales o locales según el nivel de delegación de competencias del sistema descentralizado de cada país, la visión estratégica del desarrollo del territorio que emerge se orienta hacia la prospectiva y la acción. El contrato es lo que podríamos denominar un factor de integración de las apuestas de los actores de un territorio.

El segundo aporte se evidencia en que, a través de la conclusión de los acuerdos que se formalizan en contratos, se puede promover el encuentro de un gran número de actores que hacen la vida política, 
económica y social de un territorio, pero que en otros contextos se ignoran, se enfrentan o pueden simplemente defender intereses diferentes. Los contratos de acción pública son pues un factor de apalancamiento de las iniciativas de los actores de un territorio y un factor de dinamización de la participación.

Para ilustrar estos dos primeros aportes, podemos mencionar dos ejemplos italianos de contractualización territorial en clave regional (tabla 1 ).

\section{Tabla 1. La programación concertada en Italia}

En Italia, desde la Ley 662 de 1996, que introduce la noción de "programación concertada", existen dos dispositivos de coordinación multiniveles para el desarrollo regional, los "acuerdos de programa marco" (APM) y los "pactos territoriales". El objetivo de estos contratos es realizar proyectos de desarrollo y acciones de impacto estratégico que tienen una cierta complejidad e involucran diversos actores: entidades y organismos de la administración central del Estado, regiones e instancias locales (provincias autónomas y municipios), y actores sociales del territorio, principalmente empresas y sindicatos. La diferencia es que los APM son documentos para un arreglo general entre la administración central y regional, liderados por la nación, mediante los cuales las partes se comprometen a realizar un plan plurianual de inversiones conjuntas; y en los "pactos territoriales" son los actores públicos locales (regiones, provincias autónomas y comunas) y privados (empresas y sindicatos) los que impulsan y asocian a los organismos de la administración pública nacional. En el caso italiano, predomina la búsqueda de transversalidad en la acción pública, pero se encuentran las dos perspectivas tradicionalmente opuestas del desarrollo regional, el enfoque descendente (o top-down) en los APM y el enfoque ascendente (o bottom-up) en los pactos territoriales.

El objetivo general de los $\mathrm{APM}^{12}$ es la coordinación de un gran número de actores públicos y privados involucrados en la definición del desarrollo territorial en los seis grandes sectores de intervención de las políticas públicas del Estado:

- Recursos naturales: iniciativas para la preservación y la promoción del medio ambiente focalizadas en tratamiento de aguas, basuras, energía, descontaminación de espacios naturales.

- Acción cultural: preservación y promoción del patrimonio histórico y cultural.

- Formación del recurso humano: acciones a favor del empleo en materia de educación y capacitación.

- Desarrollo local: promoción de iniciativas para el desarrollo de las condiciones de producción de un territorio, apoyo a dispositivos de comercialización y exportación, creación de procesos de producción innovadores y avances tecnológicos.

- Desarrollo urbano: apoyo a iniciativas de servicios sociales en las ciudades y a propuestas de las comunidades. 
- Información y servicios en red: apoyo a iniciativas de transportes, telecomunicaciones, innovación y seguridad.

Los APM son representativos de una forma de contractualización que facilita la integración de las apuestas en un territorio dado.

Los pactos territoriales se concentran en resolver los obstáculos que frenan la productividad y la competitividad de los territorios, mejorando el contexto en el cual los actores productivos operan o pueden surgir, y apoyando a las empresas individuales con incentivos fiscales o salariales. Los pactos son representativos de una mayor participación de los actores del territorio y han logrado amplificar las economías de escala externas tangibles (infraestructuras, servicios) e intangibles (capacidad relacional, capital social). ${ }^{13}$ Es importante mencionar que los pactos territoriales son uno de los factores que explican el éxito del modelo productivo italiano de tipo posfordista basado en las pymes especializadas en producción de bienes tradicionales o de alta tecnología, localizadas en los distritos industriales de las regiones del nordeste y centro del país (Véneto, Emilia Romagna, Toscana y Marche), las que conforman lo que se ha denominado la 'Tercera Italia', para diferenciarla del Triángulo Industrial del Noroeste (Génova, Milán y Turín) y del sur del país, más pobre y menos desarrollado.

Fuente: Elaboración del autor.

El tercer aporte se ve en la manera cómo la contractualización lleva a las autoridades a organizar la acción pública entre los diferentes actores del desarrollo. Mediante los contratos de acción pública, las prácticas de coordinación interinstitucional que aplicaban una programación directiva o una reglamentación impuesta a través de los planes nacionales de desarrollo, por ejemplo, dejan de ser la norma. Por medio de estos contratos se impone progresivamente el modelo de la negociación explícita y de la cooperación voluntaria, y se define un nuevo marco de gobernanza inclusiva. Las convenciones entre diferentes niveles de gobierno implementadas en los años noventa para controlar el crecimiento de las ciudades

\section{territarios 43}

holandesas ilustran bien este tipo de aporte (tabla 2).

El cuarto aporte tiene que ver con la sostenibilidad de los procesos de desarrollo regional. Con los contratos de acción pública se impone la práctica de la plurianualidad presupuestal. Naturalmente la reglamentación contempla esta posibilidad, pero en la práctica son muchos los obstáculos técnicos, políticos y administrativos para trascender la sacrosanta anualidad presupuestal. Con la obligatoria programación plurianual de los proyectos de los contratos de acción pública se favorece una concepción estratégica del desarrollo por los actores locales y se permite a mediano plazo una mayor visibilidad de la acción pública sobre un territorio determinado. 
Tabla 2. Los acuerdos Vinex en Holanda

El contexto urbano neerlandés es muy particular. La urbanización en los años cincuenta de este pequeño país europeo generó una concentración poblacional en una corona formada por cuatro ciudades: Ámsterdam, Rotterdam, La Haya y Utrecht. En el centro de este conjunto urbano hay un 'corazón verde' de alrededor de $50 \mathrm{~km}$ de diámetro. En los últimos 30 años, el desafío del ordenamiento territorial holandés ha sido cómo limitar el crecimiento de la conurbación policéntrica de las cuatro ciudades (que los holandeses llaman Randstad Holland o 'conurbación de Holanda') para preservar y desarrollar ese espacio verde central. Las iniciativas para regular el crecimiento urbano figuran en una ley de 1990 conocida como la Ley Vinex. ${ }^{14}$ Esta ley determina 22 zonas de construcción para las nuevas viviendas necesarias por el crecimiento poblacional y preserva el corazón verde del país promoviendo medidas que reducen la utilización de automóviles, favorecen los transportes colectivos y las formas alternativas de movilidad, y desarrollan los espacios verdes urbanos y rurales. ${ }^{15}$ Lo interesante en los contratos Vinex, fuera de sus realizaciones a veces tomadas como ejemplo de desarrollo sostenible en otros países, es el hecho de que incorporan, en su concepción misma, dos niveles de negociación explícita: una negociación multiniveles entre la nación, las provincias y los municipios, sobre las orientaciones generales y los objetivos de los acuerdos; y una negociación local entre los municipios para la implementación concreta de las medidas. El proceso no fue simple en la primera generación de Vinex, ya que el gobierno nacional, pensando que los acuerdos intercomunales iban a tardar, amenazó con retirar su apoyo a los convenios globales, por lo cual los municipios se vieron obligados a acelerar las negociaciones locales. Pero de esa manera se generó una dinámica positiva y hoy los contratos Vinex han permitido una armonización plurianual de los proyectos de vivienda, infraestructura, espacios verdes, tratamiento de aguas, transportes colectivos y zonas de urbanización futuras. ${ }^{16}$

Fuente: Elaboración del autor.

Los cuatro aportes de la contractualización a los procesos de desarrollo territorial que hemos presentado se resumen finalmente en una contribución principal: los contratos de acción pública permiten adaptar las políticas públicas a los territorios. Es decir que son un poderoso factor de territorialización de la acción pública que, sin abolir las políticas públicas sectoriales del gobierno nacional o de las entidades territoriales, determina un punto de encuentro o de convergencia entre las iniciativas de los actores políticos, económicos y sociales de cada nivel territorial, a través de la identificación y la progresiva 'institucionalización' de nuevos territorios de acción pública concertados, aquellos que definen libremente las autoridades firmantes para ejecutar los proyectos de desarrollo que se incluyen en los contratos.

El ejemplo más completo de territorialización de la planificación del desarrollo por medio de la contractualización es seguramente el del referente francés de los contratos plan colombianos, los contrats de plan Etat région (tabla 3 ).
${ }^{14}$ La apelación holandesa completa es Vierde Nota over de Ruimtelijke Ordering Extra.

${ }^{15}$ Van der Meijden (1997).

${ }^{16}$ De Bruijn, Ven Eeten y Ten Heuvenlhof (1997).

territarias 43 
${ }^{17}$ La reforma territorial de la Ley NOTRe (Nouvelle Organisation Territoriale de la République) del 7 de agosto de 2015 redujo a catorce el número de regiones francesas en el territorio metropolitano (europeo) del pais.

\section{territarios 43}

Tabla 3. Los contratos plan Estado región en Francia

Los CPER fueron creados en 1983 como una de las medidas innovadoras de la reforma de descentralización francesa del primer gobierno de izquierda de la Quinta República. Son acuerdos multisectoriales liderados por el gobierno nacional, que buscaban darle un papel de coordinación del desarrollo territorial al nuevo nivel de gobierno local, las regiones creadas como entidades territoriales en 1982. Los proyectos de desarrollo concebidos a partir de las 22 regiones políticas de aquel entonces ${ }^{17}$ se centraron inicialmente en construcción de infraestructuras de transportes ferroviario y automovilístico ( $38 \%$ de los presupuestos), inversión productiva (17\%), lucha contra el desempleo (12\%), capacitación del recurso humano $(10 \%)$ y un conjunto de iniciativas en materia de desarrollo social territorial - cultura, medio ambiente, salud, etc.- (alrededor del $23 \%$ ). Los CPER sucesivos incorporaron de manera más determinante los proyectos de desarrollo local producto de las iniciativas de cada territorio, antes de volver en la sexta generación de contratos (2014-2020) a orientaciones que articulan desarrollo estratégico y competitividad territorial. Pero es importante mencionar que, en un país con una fuerte tradición centralista, el viraje que representó en su momento la desconcentración de una parte de los recursos humanos y financieros de la administración pública hacia los territorios, y el trámite progresivo hacia la programación plurianual de la inversión pública, han sido el punto de partida de una nueva forma de planificación estratégica que ha creado un marco coherente para el desarrollo regional.

Fuente: elaboración del autor.

\section{Los obstáculos de la contractualización para el desarrollo regional}

Para asimilar el conjunto de ventajas de la utilización de los contratos de acción pública en el manejo del desarrollo regional, no podemos conformarnos con los efectos virtuosos de los procesos estudiados. Es fundamental igualmente examinar las dificultades que se presentan a las autoridades públicas en la implementación de estos contratos.

Para el análisis crítico de este tipo de medidas, debemos hacer una distinción metodológica: las dificultades o frenos al buen uso de la medida se pueden presentar en el proceso contractual en sí mismo (dentro del desarrollo procedimental, respecto de la participación financiera compartida, a los arreglos institucionales que se acuerdan, etc.), pero así mismo en los actos de gestión o de interacción que genera la implementación de la contractualización dentro del juego de actores o de instituciones, es decir, lo que podríamos llamar la sociología del proceso contractual. Sin embargo, ambos niveles están íntimamente ligados en las experiencias documentadas y los elementos del proceso contractual que originan dificultades o plantean problemas de gestión, son de alguna manera la 'otra cara de la moneda' de los aportes positivos que hemos expuesto anteriormente. 
La capacidad de apalancamiento de los proyectos e intereses de múltiples actores territoriales que permite el contrato (lo que hemos denominado la integración de las apuestas del territorio) es uno de los resultados más relevantes de la técnica contractual. El problema es que la necesidad de visibilizar estos acercamientos entre grupos de intereses diferentes o divergentes, que debe pasar obligatoriamente por la comunicación de una negociación explícita, lleva a veces a privilegiar justamente los proyectos con mayor impacto mediático y no precisamente los más estratégicos para el desarrollo regional. Las partes firmantes del contrato se pueden poner de acuerdo, justamente por la necesidad de 'hacer visibles' sus compromisos, en priorizar obras de prestigio o de ejecución inmediata, dejando para más tarde los proyectos estructurantes más costosos o cuya realización puede tomar más tiempo (infraestructuras estratégicas, programas de capacitación o de fortalecimiento institucional, por ejemplo). Es la lógica de las denominadas 'victorias tempranas', que se aplica y que frecuentemente desvirtúa la escogencia de proyectos según su valor intrínseco. De alguna manera el 'efecto palanca', que algunos buscan para generar una dinámica política y administrativa positiva o iniciar un ciclo virtuoso endógeno para el desarrollo a través de los contratos de acción pública, se convierte dentro de la práctica de la negociación en un simple 'efecto vitrina', es decir, no en la búsqueda de la eficiencia sostenible del proceso, sino en la priorización del mayor impacto inmediato, en particular en el ámbito político o mediático.

Por otra parte, un obstáculo importante en este mismo campo es el que se produce con lo que podríamos llamar la rutinización de la contractualización. ¿̇ qué aludimos aquí? Pensamos en lo que ocurre reiteradamente en las segundas o terceras generaciones de contratos de acción pública que se ejecutan sobre un mismo territorio constituido y definen un ámbito de intervención consolidado, pero al mismo tiempo sin evolución posible de una generación de contratos a la siguiente. Por ejemplo, varios estudios muestran que los componentes de algunos contratos de acción pública utilizados para propiciar el desarrollo social urbano en Francia (los actuales contratos de ciudad) no sufren modificación desde hace 20 años, como si justamente las apuestas del territorio en cada uno de los barrios populares objeto de esta política pública no variaran. ${ }^{18}$ Esta crítica se aplica a otros tantos dispositivos de acción pública ${ }^{19}$ que no cuentan con adecuados mecanismos de seguimiento evaluativo o que generan clientelas fijas entre los operadores. Existe pues un verdadero riesgo de transformación de los dispositivos contractuales en 'ventanillas' para la distribución de subsidios públicos o 'bolsas de dinero', como desafortunadamente se han presentado ocasionalmente en Colombia, fuera de toda adecuación evolutiva de los modos de asignación de los recursos
${ }^{18}$ Es una de las conclusiones del informe de la Cour des Comptes "La politique de la ville, une décennie de réformes» (2012).

${ }^{19}$ No solo a aquellos que se implementan con los contratos de acción pública.

territarias 43

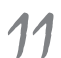


${ }^{20}$ En la acepción del concepto de Deschenaux y Laflamme (2009).

${ }^{21}$ Los brokers o mediadores del desarrollo son aquellos actores, generalmente miembros de ONG $o$ de la administración pública local, que son llamados a 'representar' a las poblaciones en las negociaciones con los financiadores externos (cooperación internacional o multilateral) o centrales (gobierno nacional). ¿Hasta qué punto estos 'traductores' de la demanda social no intervienen en realidad como 'operadores pasivos' del desarrollo? Varios estudios empíricos plantean esta problemática en Lewis $y$ Mosse (2006).

\section{territarias 43}

públicos respecto a las necesidades de los territorios.

Es indudable que la amplia participación de los actores en los procesos de perfeccionamiento de los contratos de acción pública es uno de los grandes logros de la contractualización; pero es importante tomar conciencia que la mecánica contractual hace más compleja la toma de decisiones por parte de las autoridades públicas. Esta dificultad podría anticiparse, pues proviene ante todo del aumento del número de actores presentes en las diferentes fases de la negociación. Del diagnóstico territorial inicial a la fijación de las prioridades de acción que se formalizan en los contratos, pasando por los difíciles intercambios sobre la repartición de los recursos que se deben destinar a la realización de los proyectos, pueden participar un sinnúmero de actores cuya intervención hace necesaria una metodología muy estricta que apela incluso a formas de experticia que hoy proponen los consultores privados en algunos países bajo la apelación de 'ingeniería de la negociación'. El riesgo de esta densificación del proceso de decisión, que ya se ha identificado en varios estudios de caso, es el de ver a las autoridades públicas establecer verdaderas estrategias de filtro de los actores para evitar alargar los procesos. Se puede llegar a situaciones en las cuales la negociación no reposa sobre la afiliación institucional de los participantes, sino sobre la configuración de redes informales estructuradas por las interacciones entre ciertos actores que cooptan los representantes presentes en el proceso fuera de toda designación transparente. La anécdota del 'olvido' culpable de la convocación a una reunión preparatoria a ciertos actores, por ejemplo, podría explicarse de esta manera.

A raíz de esto, hay autores que critican lo que llaman "el mito igualitarista de la contractualización” (Gaudin, 1999, p. 41), pues no solamente todos los actores no poseen los mismos recursos y competencias, o, si se quiere, el mismo capital social, ${ }^{20}$ sino que los participantes en la negociación contractual intervienen desde posiciones institucionales diferentes. Las situaciones concretas muestran que hay que reemplazar la referencia mitificada a lo que serían las virtudes intrínsecas del contrato por una sociología de los actores que manejan o intervienen en el desarrollo regional. Hay una literatura crítica sobre la implementación de los procesos de desarrollo que ayuda a comprender lo que está en juego con respecto a este obstáculo a la vez procedimental y de gestión. Los trabajos sobre la cooperación internacional y el direccionamiento de la denominada 'renta del desarrollo' que representan los fondos de las organizaciones multilaterales en particular ponen en evidencia una verdadera desigualdad de poder de acción de las diferentes categorías de actores que participan en los procesos complejos de decisión y orientación de la planificación del desarrollo. En estos estudios se ha podido referenciar la figura del broker o mediador del desarrollo, ${ }^{21} \mathrm{y}$, 
en el campo de la movilidad de las innovaciones tecnológicas, la de las diásporas del conocimiento. ${ }^{22}$ En otros campos de la acción pública aparecen, no en primera línea, sino en una especie de back-office decisional, los "emprendedores" de la mediación institucional, ${ }^{23}$ que juegan un papel, sin duda complejo y ambivalente, pero a veces decisivo, en la facilitación, la concretización de la viabilidad económica o la finalización política de los proyectos de desarrollo territorial.

Los procesos de contractualización han dado la pauta para perfeccionar formas de organización de la gestión pública más inclusivas en la gobernanza del desarrollo regional. La instauración de las fases procedimentales del contrato (diagnósticonegociación-compromiso-firma-ejecución) $y$, en particular, la elaboración compartida de los diagnósticos territoriales y la negociación explícita y mediatizada pueden constituir avances dentro de la organización de las relaciones entre actores del desarrollo regional. Considerando las conclusiones de la evaluación de los contratos plan pilotos colombianos (CNC, 2017), esta dimensión de la práctica contractual podría ser especialmente beneficiosa en el contexto de territorios agobiados por la captación corrupta o coaccionada de los recursos públicos, como es el caso de algunos en Colombia, en particular en las zonas rurales, de frontera o en espacios naturales expuestos desde varias décadas al conflicto. Pero, fuera de que una buena parte de los mecanismos administrativos o ciudadanos actuales de vigilancia de la gestión pública, tales como el control de gestión, las veedurías o los mecanismos de rendición de cuentas, se aplican poco a los contratos de acción pública en los países que los practican, es importante anotar que el marco mismo de la relación contractual trae un riesgo de gobernanza asimétrica. ¿Por qué? Porque el gobierno nacional siempre tiene la capacidad unilateral de volver sobre sus compromisos financieros por vía legislativa o por adaptación reglamentaria, sin olvidar que también los ejecutivos electos de las entidades territoriales cambian y de un período de gobierno a otro pueden reorientar las prioridades de inversión. En consecuencia, la posibilidad de sustraerse al compromiso de financiación de proyectos a largo plazo, interrumpiendo su participación y, en consecuencia, la ejecución de un proyecto al final de un período de gobierno o al término de un primer contrato, puede presentarse; tanto para los firmantes nacionales como para las autoridades locales está siempre abierta, pues justamente el contrato de acción pública es de libre adhesión para las partes. ${ }^{24}$ Sin embargo, la elaboración de los contratos de acción pública se basa en una configuración institucional en la cual una de las partes, en general el gobierno nacional, es a la vez 'juez y parte', ya que participa en la negociación y la ejecución, y se define como garante de los procedimientos que conducen a los acuerdos y a la realización de las obras. Hay que reconocer que en la
${ }^{22}$ Estas diásporas son las que constituyen expatriados altamente cualificados de paises del sur trabajando en los departamentos de ciencia y tecnología de universidades de paises del norte que participan activamente en el desarrollo de sus paises de origen (Meyer, 2004).

${ }^{23}$ Los actores que intervienen como 'emprendedores institucionales' son aquellos que manifiestan un interés por promover ciertos acuerdos institucionales, y que para ello buscan apalancar recursos que permitan crear nuevas instituciones o transformar las ya existentes (Garud et al., 2007).

${ }^{24}$ Respecto al tema de la obligación juridica que conlleva la suscripción de contratos de acción pública, la jurisprudencia ba evolucionado. En Francia, por ejemplo, un juez administrativo reconoció en 2007 la responsabilidad del gobierno nacional en la no realización de una línea de tren de alta velocidad en la región de Bordeaux inscrita en un contrato plan. El ministerio incriminado habia expuesto ante el juez que el compromiso inicial podía cumplirse con la simple modernización de

$\Longrightarrow$

territorias 43

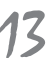


$\Leftarrow$

la via férrea existente. La sentencia del Consejo de Estado no aceptó este argumento y obligó al gobierno nacional a ejecutar el trayecto objeto del compromiso contractual (una nueva línea de alta velocidad), considerando que el contrato plan es un "convenio que da lugar a compromisos". Cf. arrêt "Région du Limousin", Conseil d'Etat, 21 décembre 2007. Recuperado de https:// www.legifrance.gouv.fr/ affichJuriAdmin.do?oldAction $=$ rechJuriAdmin \& idTexte $=$ CETATEXT000018 007958 \& fastRe $q I d=904726416$ erfast Pos $=1$

\section{territarias 43}

práctica de la gran mayoría de países que utilizan los contratos de acción pública no se han definido ni un marco normativo específico ni unas instancias de regulación que garanticen la igualdad formal y procedimental entre las partes que participan en el proceso contractual.

En lo que respecta a la sostenibilidad de los procesos de desarrollo regional, indicábamos antes que uno de los logros de la contractualización es que no solo promueve, sino que incluso obliga a pensar la acción pública dentro de la temporalidad de la programación plurianual, valga decir, en un mediano plazo que riñe con el cortoplacismo presupuestal. Este punto es difícilmente criticable, aunque su puesta en práctica plantee frecuentemente una serie de problemas técnicos y jurídicos. El principal problema indirecto, en particular desde el punto de vista de los recursos del gobierno nacional, está en el riesgo de reforzar las desigualdades territoriales que conlleva esta manera de administrar los recursos públicos. En efecto, la decisión de financiar un conjunto de obras sobre varios ejercicios presupuestales a través de mecanismos de tipo vigencias futuras, por ejemplo, tiene un componente loable de priorización estratégica del gasto que, sin embargo, hipoteca la capacidad de adaptación a las evoluciones de coyuntura de las afectaciones sucesivas por parte de las autoridades locales en particular.

Por otro lado, hay que considerar igualmente que la lógica contractual puede dar lugar a verdaderas 'transferencias escondidas de competencias' sin la asignación de los recursos correspondientes, que pueden generar desigualdades en la repartición general de los presupuestos por parte del gobierno nacional. Un ejemplo en Francia: la firma de contratos locales de seguridad en varias ciudades que han conducido a la creación o al fortalecimiento de la policía municipal (financiada por el municipio) permiten luego al gobierno nacional, sin concertación con las autoridades locales, retirar el pie de fuerza de la policía nacional (financiada por el Ministerio del Interior), de tal manera que se puede decir que el proceso completo penaliza ese mismo territorio que se consideraba beneficiado inicialmente por el contrato de acción pública correspondiente.

Por último, hay un punto puramente pragmático dentro de los actos de gestión que caracterizan la elaboración de los contratos de acción pública y que puede ocasionar una serie de obstáculos al buen manejo del desarrollo regional. Los operadores de ese tipo de dispositivos (personal electo o administrativo, actores de la sociedad civil, emprendedores) saben que la principal dificultad de la implementación de esta técnica de gestión pública es hacer coincidir las diferentes temporalidades que entran en juego en este tipo de procesos. Si consideramos los actos de gestión o de interacción que caracterizan la cronología procedimental de un contrato de acción pública, su práctica operativa contrapone los tiempos de las administraciones y los tiempos de los procesos sociales. Ya 
entrando en detalle habría que tomar en cuenta, fuera del tiempo incompresible de la legislación y de la reglamentación:

- el tiempo apretado de la ingeniería de proyecto;

- el tiempo extensible de la negociación en el cual se podría distinguir un tiempo social de la toma de conciencia colectiva y un tiempo efervescente para el acuerdo político;

- y, en la fase de implementación, el tiempo metódico de la coordinación, el tiempo largo de la ejecución y la temporalidad, frecuentemente ocultada, del seguimiento evaluativo, de la concertación arbitral y de la rendición de cuentas.

Para decirlo de otra manera: para concertar objetivos de desarrollo por contrato, hace falta tiempo, mucho tiempo. Sin embargo, el tiempo que generalmente se asigna a esos procesos está dramáticamente contabilizado y limitado porque in fine no puede concebirse más allá de la agenda política de la negociación nacional-local o intralocal.

\section{Conclusiones o reflexiones finales: condiciones para concertar por contrato objetivos para territorializar el manejo del desarrollo}

Naturalmente la complejidad del manejo del desarrollo territorial excluye cualquier tipo de receta metodológica unívoca, en particular para el último obstáculo mencionado. Sin embargo, siguiendo el curso del análisis efectuado a partir de las experiencias extranjeras que hemos comentado, se puede responder a la pregunta ¿por qué concertar por contrato el desarrollo territorial? con la siguiente respuesta matizada:

- porque es necesario integrar todas las apuestas y desafíos de los territorios, evitando al máximo la priorización de acciones bajo el 'efecto vitrina' y la rutinización de la programación contractual;

- porque a través de la contractualización se puede facilitar la participación de los actores representativos del territorio, eso sí sin complejizar los procesos de toma de decisiones y teniendo en cuenta el papel de todos los intermediarios legítimos de la negociación;

- porque hoy se requieren nuevas formas de organización de la acción pública que permitan hacer vivir una verdadera gobernanza inclusiva, definiendo necesariamente un marco y unas instancias de regulación que garanticen la igualdad formal y procedimental entre las partes;

- porque concertar mediante contratos de acción pública permite promover una perspectiva sostenible del desarrollo con una visión estratégica del territorio amparada en una práctica plurianual del gasto público, en la 
medida en que no se pierdan de vista los riesgos de intensificación de las desigualdades territoriales existentes a escala nacional.

En resumen, si en la implementación de los contratos de acción pública no se descartan las contingencias que impone la gestión compleja de las múltiples temporalidades sociales, políticas, administrativas y técnicas, la contractualización que representan hoy en Colombia de cara al futuro los pactos territoriales puede favorecer una adecuada territorialización del manejo del desarrollo. Lo que nos parece esencial es que los contratos de acción pública tienen todos los elementos operativos para ser instrumentos generadores de sostenibilidad de los mecanismos de gobernanza territorial bien calibrados para los procesos políticos cada vez más necesarios en la implementación de las políticas públicas en una nación como Colombia, que hoy aspira a potenciar su organización territorial descentralizada.

\section{Referencias}

Carmona, R. (2006). Los pactos territoriales en Italia. Un análisis de la experiencia reciente y sus implicancias en términos de governance. EURE, XXXII(96), 117-133.

Charbit, C., \& Mizell, L. (Comps.). (2007). Linking regions and central

\section{territorias 43} governments. Contracts for regional development. OCDE.
Charbit, C., \& Romano, O. (2017). Governing together: an international review of contracts across levels of government for regional development. Regional Development Working Papers 2017/04. OCDE.

De Bruijn, H., Ven Eeten, M., \& Ten Heuvenlhof, E. (1997). L'administration négociée aux Pay-Bas: leçons de quelques recherches empiriques sur les processus de contractualisation dans les réseaux métropolitains. En G. Marcou, F. Rangeon \& J.-L. Thiebault (Comps.), La coopération contractuelle et le gouvernement des villes (pp. 347384). L'Harmattan.

Deschenaux, F., \& Laflamme, C. (junio 2, 2009). Réseau social et capital social: une distinction conceptuelle nécessaire illustrée à l'aide d'une enquête sur l'insertion professionnelle de jeunes Québécois. SociologieS.

De la Torre, L. (2012). Marco conceptual para la implementación del instrumento contratos plan en Colombia. DNP.

De la Torre, L. (2018). La fabrique des territoires de l'action publique: l'avènement des contratos plan en Colombie (Tesis para la obtención del título de Doctor en Geografía y Ordenamiento del Espacio, U. Paul Valéry de Montpellier, Francia).

Di Meglio, R. (2004). Los pactos territoriales en la experiencia italiana. OIT.

Dumoulin, L., \& Saurugger, S. (2010). Les «policy transfer studies», analyse 
critique et perspectives. Critique Internationale, 48.

Garud, R., Hardy, C., \& Maguire, S. (2007). Institutional entrepreneurship as embedded agency: an introduction to the special issue. Organization Studies, 28(7), 957-969.

Gaudin, J.-P. (1999). Gouverner par contrat: l'action publique en question. París: Presses de Sciences Po.

González, F. D. (2013). Consideraciones jurídicas sobre la figura de los contratos plan en Colombia. En L. Estupiñán Achury \& M. Restrepo (Comps.), Asociatividad territorial: enfoque comparado y análisis en el nuevo contexto de la organización territorial colombiana (pp. 307-337). Editorial Universidad del Rosario.

Lascoumes, P., \& Le Galès, P. (2004). Gouverner par les instruments. París: Presses de Sciences Po.

Le Galès, P. (2019). Gouvernance. En L. Boussaguet (Ed.), Dictionnaire des politiques publiques ( $5^{\mathrm{e}} \mathrm{ed}$.) (pp. 297305). Paris: Presses de Sciences Po.

Lewis, D., \& Mosse, D. (Eds.). (2006). Development brokers and translators: the ethnography of aid and agencies. West Hartford: Kumarian Press Inc.
Meyer, J.-B. (2004). Les diasporas de la connaissance: atout inédit de la compétitivité du Sud. Revue internationale et stratégique, (55), 69-76.

Tavares, M., \& Berretta, N. (2006). Sistemas de planificación estratégica e innovaciones presupuestarias. Informe del Banco Interamericano de Desarrollo para el Plan de Acción a Mediano Plazo para la Efectividad en el Desarrollo (Prodev). Van der Meijden, J. (1997). Pays-Bas, les projets Vinex: le cas d'Utrecht et Vleuten-de-Meern in L'élaboration des projets architecturaux et urbains en Europe. Vol 1. Les acteurs du projet architectural et urbain. Ecole d'Architecture de Bordeaux.

\section{Informes colectivos}

Ciudades y Gobiernos Locales Unidos. (2007). Primer informe mundial sobre la descentralización y la democracia en el mundo. Barcelona.

CNC. (2017). Evaluación de operaciones e impacto de los contratos plan. Centro Nacional de Consultoría para el Departamento Nacional de Planeación.

Cour des Comptes. (2012). La politique de la ville, une décennie de réformes. Paris. 